\title{
Hip Fractures Risk and Postoperative Period in Elderly Diabetic Patients
}

\author{
Pawel Skowronek, Pawel Piatkiewicz, ${ }^{*}$ Andrzej Lewandowicz ${ }^{3}$ and Agnieszka Maksymiuk-Klos ${ }^{2}$ \\ ${ }^{1}$ Department of Orthopaedics and Traumatology; Regional Hospital WSZZ Kielce, Jan Kochanowski University, Poland \\ ${ }^{2}$ Department of Internal Medicine, Diabetology and Endocrinology, Warsaw Medical University, Poland \\ ${ }^{3}$ Department of Geriatrics, National Institute of Geriatrics, Rheumatology and Rehabilitation, Spartanska 1, 02-637 Warsaw, Poland \\ *Corresponding author: Pawel Piatkiewicz, Department of Internal Medicine, Diabetology and Endocrinology, Warsaw Medical University, Poland, Tel: +48 22 3265817; \\ E-mail: piatkiewicz@op.pl
}

Received date: May 15, 2017; Accepted date: June 08, 2017; Published date: June 13, 2017

Copyright: (C) 2017 Skowronek P, et al. This is an open-access article distributed under the terms of the Creative Commons Attribution License, which permits unrestricted use, distribution, and reproduction in any medium, provided the original author and source are credited.

\begin{abstract}
Hip fractures with the numbers about 1.6 million over the world in 2000 are serious health problem which drastically limits the functionality and increases mortality in geriatric population. Peritrochanteric and neck hip fractures result from the reduction of mineral bone density or impaired quality, however age related co-morbidities add additional risk related to increased incidence of falls. The one of the diseases found to increase hip fractures incidence and associated mortality is diabetes which currently affects 415 million adults over the world with increasing prevalence, predicted to 642 million by 2040. Type 1 diabetes contributes to fragility by unfavorable changes in bone metabolism. Although type 2 diabetes effects on bone may be paradoxically opposed, it still increases risk of falls and hip fractures. The causes of increased fractures risk via precedent falls comprise of diabetic angio and neuropathic complications affecting central nervous system, vision, balance and also results from polypharmacy. Diabetes influences also the postoperative period, deteriorating wounds healing and promoting sores formation. The scope of diabetes impact on hip fractures risk and orthopaedic surgery results should be particularly considered together with proper glycemic control to prevent postoperative complications and improve patient prognosis.
\end{abstract}

Keywords: Hip fracture risk; Diabetes complications; Sarcopenia; Hypoglycaemic

\section{Introduction}

In the light of demographic changes the participation of elderly people in populations of Europe countries, as well as in United States of America increases, which although adds a huge value to societies, is an unusual and difficult challenge for national healthcare systems. It is estimated that American population aged 65 and above will increase from $14.5 \%$ ( 46.2 million) in the year 2014 to $21.7 \%$ of the population by 2040 , and by the 2060 there will be 98 older persons, more than twice their number in 2014 [1]. In the European Union countries (the Eurostat database), consistently with reduced births rates and higher life expectancy, there is forecast for an increasing share of the aged 65 years or over in total population from $18.9 \%$ in 2015 (96 million) to $28.7 \%$ by 2080 ( 149 million) with adjustment for projected population size of 520 million (EUROPOP2013) [2]. The prolonged the individual life-time, connected with a better healthcare, also the longer time needed to the progression of time-dependent chronic diseases complications especially affecting functionality. Those include atherosclerosis with cardiovascular disease affecting heart and diminished physical efficiency; involvement of central nervous system with brain lesions, stroke or neurodegeneration limiting mental or physical activity and leading to dementia; the narrowing of the arteries of lower extremities causing intermittent claudication with pain and mobility disturbances. Father, the cancers distinctive for older age, associates with malnutrition or cachexia. Those exacerbate sarcopenia which influence the physical level of activity exacerbating frailty [3]. The osteoporosis, rheumatoid chronic diseases and arthropathies revealing especially in elderly, impair mobility, decrease bone quality and together with other risk factors contribute to life-threatening fractures. The diabetes is a worldwide epidemics and an exceptional chronic condition connected with many co-morbidities causing faster decline in functionality. It seems, however, that there is also an association between diabetes and sudden health problem such a bone fracture. The surprising correlation of diabetes and hip fractures risk in elderly emphasize particular precaution against falls in older patients with diabetes. It also urges to appropriate glycemic control in the term of peri- and postoperative regimen if fracture occurred and orthopaedic surgery has to be performed but complications are to be minimized.

Approximately 1.6 million hip fractures occur worldwide each year, by 2050 this number could reach between 4.5 million and 6.3 million [4]. For the year 2000, there were an estimated 9 million new osteoporotic fractures, of which 1.6 million were at the hip, 1.7 million were at the forearm and 1.4 million were clinical vertebral fractures [5]. The number of fractures increases with patient age. Hip fractures cause the most morbidity with reported mortality rates up to $20-24 \%$ in the first year after a hip fracture, and greater risk of dying may persist for at least 5 years afterwards. Loss of function and independence among survivors is profound, with $40 \%$ unable to walk independently, $60 \%$ requiring assistance a year later [6-8]. The data of new fractures total number in Poland are limited. In 2005, according to National Health Fund in Poland, 15888 people over 50 years of age were operated with hip fractures [9]. Jaworski and Lorenc on the Mazovian population basis, estimated the number of these fractures at 27434 , which determines the incidence of 280 [10].

Diabetes mellitus (DM) is one of the most important causes of mortality and morbidity in older subjects. Currently 415 million adults have diabetes, by 2040 diabetic population will rise to 642 million [11]. In Poland the number patients with diabetes reaches almost 3 million people [11]. The main aim of diabetic patients treatment is the late complications prevention-diabetic neuropathy and angiopathy. The important goals of good control of diabetes are normoglycemia and 
HbAlc value below 7\%. The good metabolic control especially in elderly people is associated with a higher risk of hypoglycemia. According to the ADA 2016 recommendations in patients with type 2 diabetes good metabolic control means $\mathrm{HbAlc}<6.5 \%$ in short- term cases and $7 \%$ for others. The exception is the elderly (patients aged over 70 years) with longstanding diabetes $>20$ years with co-occurring significant macrovascular complications. In this group, HbA1c level equal or below $8 \%$ is sufficient [12]. Piatkiewicz et al. proved that low HbAlc level indicates inappropriate intensification of the diabetes treatment and it is associated with higher risk of severe hypoglycaemic episodes in elderly. The most severe hypoglycaemic episodes have been reported in sulphonylurea or insulin-treated type 2 diabetic patients. One of the reasons for life-threatening hypoglycaemia is overtreatment of diabetes in old patients, proven by the invalid values of $\mathrm{HbAlc}$ obtained in this study, which are clearly lower than those recommended by the ADA and PTD. The authors noted that low glucose levels can also lead to falls resulting in fractures and traffic accidents [13].

As the result of long disease duration and associated complications, patients medical care costs with this disease are approximately two times higher as compared to the healthy subjects [14].

In type 1 diabetes (T1DM) reduction of the bone mineral density (BMD) is a result of insulin deficiency. This occurrence partially explains the greater susceptibility to fractures in diabetic group of patients [15]. Also some observational studies on patients with type 2 diabetes (T2DM) with osteoporotic fractures indicated increased fractures incidence compared to patients without this disease, but results are inconsistent [16]. Interesting fact is that while a low BMD is consistently observed in people with T1DM, in T2DM bone mineral density is normal or higher than in non-diabetic patients [17]. Such paradox has no one explanation; it is complex and may be explained by many factors. Especially two of them: an increased rate of fall risk and lower bone quality seems to be important $[18,19]$.

According to Burghardt et al. observation in patients with T2DM trabecular bone structure is intact or enhanced, whereas it is the cortical bone that is preferentially compromised [20,21]. Such observation is relevant and important as the cortical bone builds $80 \%$ of the skeleton and fractures in people with DM often occur in places rich in cortical bone [22].

One of the largest retrospective cohort studies compared risk of the hip fracture was made in an elderly Canadian population. It compared women and men with diabetes over a 6-year follow-up period [22]. The study showed that diabetes increased hip fracture risk by $18 \%$ in men and by $11 \%$ in women, after taking into account potential interfering factors, including co-morbidities, age and drugs that increased the risk of falls. [22]. New Swedish investigation from 2017 showed that in patients with insulin treated T2DM, the risk of hip fracture was higher in man and women. T2DM-treated with the oral diabetic drugs was related to increased hip fracture only in women [23].

Janghorbani et al. published a meta-analysis of studies involving a total of more than 800000 T1DM and T2DM patients, and reported a positive association between $\mathrm{T} 2 \mathrm{DM}$ and any foot fracture, nonvertebral fracture, and hip fracture [24]. According to this analysis the association between diabetes and hip fracture also persisted after adjusting for age, body mass index. physical activity, and tended to be stronger in men than in women and in long-standing diabetes $[24,25]$.
A total of 15 observational studies (11 cohort and 4 cross-sectional, 263006 diabetics and 502115 controls) diabetes was demonstrated to increase the risk of hip fractures by $29.6 \%(\mathrm{P}=0.008)$ [16]. It also supports the association between T2DM and increasing of hip fracture risk in postmenopausal women.

Two huge cohort studies: the ABC Health Study and a Swedish population study reported higher fracture incidence in diabetic patients with peripheral neuropathy [26]. Also this studies results suggested that peripheral vascular diseases seem to be inversely correlated with BMD in the diabetic population [26,27].

Ivers et al. described in an older Australian population, that diabetic patients with complication like a retinopathy also presented a higher fractures risk (five times more) than that observed in patients without such complication [28]. Similarly, Schwartz et al. found that low physical activity, falls, and the use of benzodiazepines accounted for the association between diabetes and fractures [29].

According to Gulcelik et al. diabetic patients with hip fracture had a higher risk of mortality than the non-diabetic patients. They found that one year survival probabilities of non-diabetic and diabetic patients were respectively $87.3 \%$ and $68.0 \%(p=0.033)$ [30].

Due to an increased risk of mortality after hip fracture in diabetic patients the post-operative medical care especially glycemic control and postoperative complications prevention, should be optimized in order to decrease mortality in these group of patients [17].

In summary, in type 1 diabetes reduction of the bone mass density (BMD) explains increased susceptibility to fractures. However, patients with type 2 diabetes generally have normal or even increased BMD. This apparent occurrence may be explained by the fact that, at a given level of BMD, diabetic patients present lower bone quality with respect to non-diabetics, as shown by several studies reporting that diabetes may affect bone tissue by means of various mechanisms, including hyperinsulinemia, deposition of advanced glycosylation endproducts in collagen, renal failure, reduced serum levels of GF-1, hypercalciuria, microangiopathy and inflammation [15,17-19,28-30].

Carpintero et al. observed that poor glycemic control is a common preoperative complication of diabetic patients with hip fracture surgery. Abnormal blood glucose level is additionally associated with an increased risk of perioperative infection and a life-threatening asymptomatic coronary artery disease [30]. It seems that especially malnutrition and diabetes are clearly related to deep, serious infections [31]. Treatment of wounds in all elderly patients results in worse outcomes. Diseases (multiple comorbidities, diabetes, dementia or cognitive impairment, cancer, cardiac disease) and eating disorders further aggravate this problem [32].

In 2017 Reateqiu et al. evaluated the reduction of postoperative complications in patients after orthopedic surgery with particularly, good controlled diabetes mellitus. After surgery and discharge from the hospital, the patients were transferred to PCP (Primary Care Provider), who was responsible for proper treatment and control of glycaemia. Patients who did not participate in PCP care had an independent predictor of medical complications of surgical infections and mechanical complications. The study confirmed that decrease HbAlc level is related to less medical complications [33].

One of the most important and serious causes of musculoskeletal system infections in the elderly is osteomyelitis. Elderly patients have an increased incidence of predisposing disorders to osteomyelitis (such as diabetes, atherosclerosis or caries). In addition, the number of 
surgical procedures in the elderly population increases with aging (e.g., teeth removal, open heart surgery and orthopedic surgery) [34]. Surgical procedures, especially those relating to the skeletal system, are an additional risk factor for osteomyelitis. The most commonly occurs organisms associated with osteomyelitis in patients with diabetes mellitus are $S$. aureus, group B streptococci, aerobic gram-negative bacilli, and B. fragilis [345902078020001]. The osteomyelitis represents a significant risk of complications after hip fractures in elderly diabetic patients.

\section{Conclusion}

Diabetes is one of the most common illnesses in the elderly people. It not only causes numerous complications including most often described vascular and neurological but additionally increases the risk of fractures. The incidence of life-threatening hip fractures, which drastically deteriorate precedent functionality, is increasing with aging of population. The causes of fractures always remain complex, combining external factors such as an increased risk of falls in the geriatric population and also metabolic causes leading to change in bone mineral quality and increase in fragility. There are also some differences among bone mass density in type 1 and type 2 diabetes. Recent studies have also shown the effect of antidiabetic treatment on fractures frequency. Hip fracture risk associated with diabetes as civilization disease of increasing prevalence, and specificity of diabetic perioperative complications in orthopaedic surgery should be emphasized to undertake proper management enabling the most favorable recovery.

\section{References}

1. Administration for Community Living (2016) U.S. Department of Health and Human Services.

2. Population structure and ageing in Europe (2016) Eurostate database.

3. Viana JU, Silvia SL, Torres JL, Dias JM, Pereira LS, et al. (2013) Influence of sarcopenia and functionality indicators on the frailty profile of community-dwelling elderly subjects: a cross-sectional study. Braz J Phys Ther 17: 373-381.

4. Gullberg B, Johnell O, Kanis JA (1997) World-wide projections for hip fracture. Osteoporos Int 7: 407.

5. Johnell O, Kanis JA (2006) An estimate of the worldwide prevalence and disability associated with osteoporotic fractures. Osteoporos Int 17: 1726.

6. Leibson CL, Tosteson AN, Gabriel SE, Ransom JE, Melton LJ (2002) Mortality, disability, and nursing home use for persons with and without hip fracture: a population-based study. J Am Geriatr Soc 50: 1644.

7. Magaziner J, Lydick E, Hawkes W, Fox KM, Zimmerman SI, et al. (1997) Excess mortality attributable to hip fracture in white women aged 70 years and older. Am J Public Health 87: 1630.

8. Riggs BL, Melton LJ 3rd (1995) The worldwide problem of osteoporosis: insights afforded by epidemiology. Bone 17: 505S.

9. NFZ database, Poland.

10. Jaworski M, Lorenc RS (2007) Risk of hip fracture in Poland. Med Sci Monit. 13: CR 206-210.

11. IDF Alas (7thedn).

12. Piątkiewicz P (2016) Hypoglycemia in Elderly Type 2 Diabetes Patients. Journal of Clinical Diabetes \& Practice. 1: 2.

13. Piatkiewicz P, Buraczewska-Leszczynska B, Kuczerowski R, BernatKarpinska M, Rabijewski M, et al. (2016) Severe hypoglyceamia in elderly patients with type 2 diabetes and coexistence of cardiovascular history. Kardiologia Polska 74, 8: 779-785.
14. Yang W, Dall TM, Halder P et al (2013) American diabetes association. economic costs of diabetes in the U.S. in 2012. Diabetes Care 36: 1033-1046.

15. Montagnani A, Gonnelli S, Alessandri M, Nuti R (2011) Osteoporosis and risk of fracture in patients with diabetes: an update. Aging Clin Exp Res. 23: 84-90.

16. Dytfeld J, Michalak M (2017) Type 2 diabetes and risk of low-energy fractures in postmenopausal women: meta-analysis of observational studies. Aging Clin Exp Res. 29: 301-309.

17. Isidro M, Ruano B (2010) Bone disease in diabetes. Curr Diabetes Rev 6: 144-155.

18. Carnevale V, Romagnoli E, D'Erasmo E (2004) Skeletal involvement in patients with diabetes mellitus. Diabetes Metab Res Rev 20: 196-204.

19. Schwartz AV, Hillier TA, Sellmeyer DE, Resnick HE, Gregg E, et al. (2002) Older women with diabetes have a higher risk of falls: a prospective study. Diabetes Care 25: 1749-1754.

20. Burghardt AJ, Issever AS, Schwartz AV, Davis KA, Masharani U, et al. (2010) High-resolution peripheral quantitative computed tomographic imaging of cortical and trabecular bone microarchitecture in patients with type 2 diabetes mellitus. J Clin Endocrinol Metab 95: 5045-5055.

21. Leslie WD, Rubin MR, Schwartz AV, Kanis JA (2012) Type 2 diabetes and bone. J Bone Miner Res 27:2231-2237.

22. Lipscombe LL, Jamal SA, Booth GL, Hawker GA (2007) The risk of hip fractures in older individuals with diabetes: a population-based study. Diabetes Care 30: 835-841.

23. Janghorbani M, Van Dam RM, Willett WC, Hu FB (2007) Systematic review of type 1 and type 2 diabetes mellitus and risk of fracture. Am J Epidemiol 166: 495-505.

24. Wallander M, Axellson KF, Nilsson AG, Lundh D, Lorentzon M (2017) Type 2 Diabetes and Risk of Hip Fractures and Non-Skeletal Fall Injuries in the Elderly: A Study From the Fractures and Fall Injuries in the Elderly Cohort ( FRAILCO). J Bone Miner Res 32: 449-460.

25. Adami S (2009) Bone health in diabetes, considerations for clinical management. Current Med Res Opin 25: 1057-1072.

26. Strotmeyer ES, Cauley JA, Schwartz AV, Nevitt MC, Resnick HE, et al. (2005) Nontraumatic fracture risk with diabetes mellitus and impaired fasting glucose in older white and black adults: the Health, Aging, and Body Composition Study. Arch Intern Med 165: 1612-1617.

27. Miao J, Brismar K, Nyren O, Ugarph-Morawski A, Ye W (2005) Elevated hip fracture risk in type 1 diabetic patients: a population- based cohort study in Sweden. Diabetes Care 28: 2850-2855.

28. Ivers RQ, Cumming RG, Mitchell P Peduto AJ, Blue Mountains Eye Study (2001) Diabetes and risk of fracture: The Blue Mountains Eye Study. Diabetes Care 24: 1198-1203.

29. Schwartz AV, Sellmeyer DE, Ensrud KE, Cauley JA, Tabor HK, et al. (2001) Older women with diabetes have an increased risk of fracture: a prospective study. J Clin Endocrinol Metab 86: 32-38.

30. Gulcelik NE, Bayraktar M, Caglar O, Alpaslan M, Karakaya J (2011) Mortality after hip fracture in diabetic patients. Exp Clin Endocrinol Diabetes 119; 414-418.

31. Carpintero P, Caeiro JR, Carpintero R, Morales A, Silva S, et al. (2014) Complications of hip fractures: A review. World J Orthop 5: 402-411.

32. Colon-Emeric CS (2012) Postoperative management of hip fractures: interventions associated with improved outcomes. Bonekey Rep 1: 241.

33. Reategui D, Tornero E, Popescu D, Sastre S, Camafort M, et al. (2016) Postoperative hyperglycaemia control reduces postoperative complications in patients subject to total knee arthroplasty. Knee 24: 128-136.

34. Yoshikawa TT, Cunha BA (2002) Osteomyelitis in Elderly Patients. Clin Infect Dis 35: 287-293. 